\title{
ИЗМЕНЕНИЕ НАРУШЕННОСТИ ЛЕСНЫХ ЭКОСИСТЕМ ЛЕСОСТЕПНОЙ ЗОНЫ ЦЕНТРАЛЬНОГО ЧЕРНОЗЕМЬЯ В КОНЦЕ ХХ-НАЧАЛЕ ХХI ВЕКА
}

\author{
(C) 2020 г. Э. А. Терехин* \\ “Белгородский государственный национальный исследовательский университет”, \\ Федерально-региональный центр аэрокосмического и наземного мониторинга объектов и природных ресурсов, \\ Белгород, Россия \\ *E-mail: terekhin@bsu.edu.ru \\ Поступила в редакцию 28.11.2019 г.
}

\begin{abstract}
Изложены результаты оценки нарушенности древостоя лесных экосистем лесостепной зоны Центрального Черноземья в периоды 1985-2000 гг. и 2000-2018 гг. С использованием автоматизированного подхода выполнено геоинформационное картографирование участков нарушенных лесов, появившихся в соответствующие периоды времени. Доля нарушенных лесных экосистем на территории лесостепной зоны Центрального Черноземья выросла с $2.5 \%$ в конце XX в. до 6\% в начале XXI века. В хвойных лесах доля нарушенных лесных экосистем выросла в 9 раз, в лиственных лесах доля нарушенных участков выросла незначительно. Увеличение доли нарушенных лесов произошло преимущественно за счет повышения нарушенности хвойных лесных экосистем. Доля лиственных лесов в структуре нарушенных лесных экосистем наоборот снизилась почти в 2 раза. Для исследуемой территории впервые подготовлена карта категорий нарушенности лесных экосистем, характеризующая леса по времени, прошедшему с последнего воздействия нарушающих факторов.
\end{abstract}

Ключевые слова: нарушенность лесных экосистем, лесостепь, лес, данные дистанционного зондирования, Landsat, Sentinel

DOI: $10.31857 / \mathrm{S} 0205961420030069$

\section{ВВЕДЕНИЕ}

Одним из ключевых факторов, определяющих состояние лесных массивов и его многолетнюю динамику, является нарушенность древостоя. Она может быть обусловлена различными причинами, к которым в первую очередь относятся сплошные лесосечные рубки, пожары, болезни деревьев или влияние насекомых-вредителей. В связи с этим анализ изменений, связанных с нарушениями древесного полога, является необходимой задачей для оценки состояния и современных тенденций развития лесных экосистем.

Данная проблема актуальна и для лесов лесостепной зоны Центрального Черноземья, где при относительно небольшой лесистости, составляющей около 9\%, сконцентрирована значительная доля дубрав. Широколиственные леса с доминированием в древостое дуба и ясеня составляют основу земель, покрытых лесом (Харченко, 2007). По левобережьям наиболее крупных рек распространены также хвойные лесные насаждения, доля которых при этом значительно меньше суммарной площади широколиственных лесных массивов.
Разновременные спутниковые снимки являются одними из наиболее достоверных материалов, позволяющих оценить изменения в лесах, связанные с нарушенностью древесного полога (Борзов, Потатуркин, 2008; Барталев и др., 2015), что особенно актуально при проведении ретроспективных оценок (Hermosilla et al., 2016; Zhao et al., 2018; Плотникова и др., 2019).

Изменения спектрально-отражательных свойств, обусловленные влиянием негативных факторов на леса, могут быть использованы для картографирования нарушенности лесных экосистем (Потапов и др., 2008; Бондур, 2015; Воробьев и др., 2016). К настоящему на основе разновременных дистанционных данных предложены различные способы детектирования изменений в лесах, основанные на применении пар разновременных снимков и на основе многолетних рядов изображений. Необходимо отметить методы, использующие декомпозицию спектральных смесей (Барталев, 2005), алгоритмы временной сегментации (Kennedy et al., 2010), способы определения пространственных тенденций в нарушенности на основе регрессионного анализа (Vogelmann et al., 2012). На основе рядов спутниковых данных 
Таблица 1. Параметры лесных массивов, использованных для анализа изменения нарушенности древостоя лесных экосистем лесостепной зоны в конце XX в.-начале XXI в.

\begin{tabular}{l|c|c}
\hline \multicolumn{1}{c|}{ Область РФ } & Площадь лесов суммарная, га & Число лесных массивов \\
\hline Белгородская область & 147393.2 & 329 \\
Воронежская область & 270391.9 & 429 \\
Курская область & 110786.6 & 406 \\
Липецкая область & 152531.9 & 689 \\
Орловская область & 125364.5 & 439 \\
Тамбовская область & 334273.1 & 3026 \\
Всего & 1140741.2 & 34 \\
\hline
\end{tabular}

предложены подходы непрерывного выявления изменений в лесах (Brooks et al., 2014), включая методы оценки отклонений от фенологических моделей в конкретных природно-климатических условиях (Huang et al., 2010; Zhu, Woodcock, 2014). Отдельная группа методов основана на использовании спектральных индексов (Стыценко и др., 2019), включая индексы нарушенности лесных экосистем (Healey et al., 2005).

Большинство предложенных подходов показывает достаточно высокую точность выявления изменений в лесах тестовых регионов, но применение многих из них имеет ряд ограничений. Обусловлено это особенностями породного состава лесных насаждений, фенофаз и иных факторов. Вследствие этого многие методы, разработанные для картографирования измененных лесов на глобальном или крупнорегиональном уровне, недостаточно точны при выявлении изменений в лесах на уровне отдельных регионов. В связи с этим совершенствование подходов к автоматизированному картографированию участков нарушенных лесов остается актуальной задачей (White et al., 2017; Hislop et al., 2019).

Цель настоящей статьи - оценка и сравнение нарушенности древостоя лесных экосистем лесостепной зоны Центрального Черноземья в периоды 1985-2000 гг. и 2000-2018 гг. на основе многозональных спутниковых данных. Задачи исследования включали геоинформационное картографирование участков нарушенных лесов, появившихся в соответствующие временные интервалы, изучение пространственно-временных особенностей в нарушенности лесных массивов.

\section{МЕТОДИКА ИССЛЕДОВАНИЯ}

Объектом исследования выступали лесные экосистемы лесостепной зоны, расположенные в пределах Белгородской, Воронежской, Курской, Орловской, Липецкой и Тамбовской областей (рис. 1). Территория, на которой производили оценку изменения нарушенности древостоя, охватывала лесостепную зону от ее северной гра- ницы с лесной (северо-запад Орловской области) до зоны степи - на юго-востоке Белгородской и юге Воронежской областей.

Исследование выполнено на основе выборки лесных массивов, типичных для региона, и включающей, в том числе, все наиболее крупные леса, площадью более 10000 га, расположенные в его пределах. Для обеспечения репрезентативности проводимых оценок, лесные массивы для изучения отбирали таким образом, чтобы они были представлены в каждой ячейке размером $30 \times 30$ км, на которую была разбита вся территория исследования. Соответствующий размер ячеек был подобран эмпирически таким образом, чтобы обеспечить представленность анализируемых лесных участков во всех частях лесостепи Центрального Черноземья. Подбор лесных массивов для анализа осуществляли на основе совместного изучения космических снимков Landsat ТМ середины 1980-х гг. и современных более детальных снимков Sentinel 2018 года.

В общей сложности было отобрано несколько тысяч лесных массивов, суммарной площадью 1140741.2 га (табл. 1). Исследуемые леса были представлены во всех областях Центрального Черноземья, а также Орловской области.

Объективная оценка изменений в лесах, обусловленных нарушенностью древесного полога, требовала создания векторной основы всех анализируемых лесных массивов. Ее подготовка была осуществлена методом ручной оцифровки контуров лесных массивов по спутниковым данным в геоинформационной среде ArcGIS. Для подготовки векторной основы были использованы снимки Landsat TM (источник данных: https://earthexplorer. usgs.gov/) c пространственным разрешением 30 м/пиксель, полученные в середине 1980-х гг. и снимки Sentinel-2 2018 г. с пространственным разрешением 10 м/пиксель. Снимки Sentinel применялись на ряде участков для повышения точности картографирования контуров лесных массивов.

Для анализа подбирали лесные массивы, площадью не менее 1 га. Соответствующая мини- 


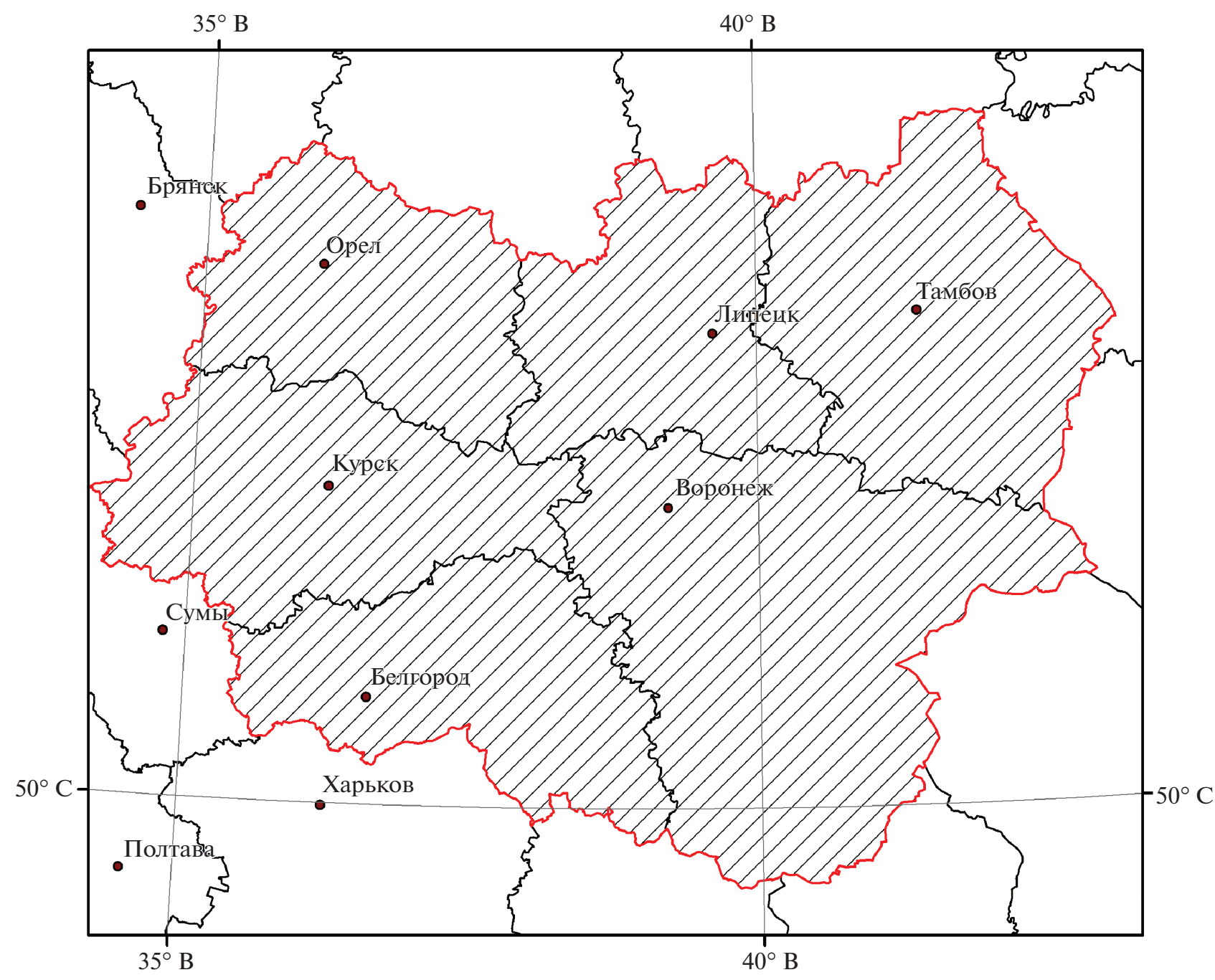

Рис. 1. Местоположение территории исследования.

мальная площадь была выбрана для обеспечения последующей объективной оценки спектральноотражательных свойств конкретных лесных участков и обусловлена величиной пространственного разрешения космических снимков Landsat (30 м/пиксель), на основе которых в дальнейшем анализировали изменение коэффициентов спектральной яркости.

В процессе оцифровки для каждого лесного массива на основе многозональных снимков Landsat фиксировался его тип (лиственный, хвойный, смешанный), что в дальнейшем позволило оценить степень нарушенности в разных типах лесных насаждений. Определение типа лесного массива осуществлялось методом анализа снимков в различных вариантах синтеза каналов. Преимущественно использовали вариант SWIR2-SWIR1-RED (2.09-2.35 мкм, 1.55-1.75 мкм, 0.63-0.69 мКм), позволяющий достаточно достоверно определять группы пикселей, соответству- ющих лиственным и хвойным насаждениям на уровне детальности снимков Landsat.

Подборка снимков, сформированная для проведения исследований, содержала следующие группы изображений:

- многозональные снимки Landsat TM, ETM+, OLI на три временных среза: середины 1980-х гг., начала 2000-х гг. и 2018 год, полученные в вегетационный период, преимущественно в сроки июля-августа;

- многозональные снимки с сенсора Sentinel-2 MSI. Соответствующая подборка снимков также полностью покрывала территорию исследования и включала 31 изображение, полученное в период лета-начала осени 2018 года.

При подборке снимков Landsat учитывали, что оптимальный период для картографирования лесов по спутниковым данным начинается через одну декаду после полного облиствения и закан- 
чивается на одну декаду раньше периода массового пожелтения листвы (Харин, Татеиши, 2003). В лесостепи ЦЧР эти сроки соответствует периоду с 20-х чисел мая по начало сентября. Для минимизации фенологических различий старались подбирать разновременные снимки таким образом, чтобы интервал между датами их получения был минимален. Подборка снимков для каждого из трех временных срезов полностью покрывала территорию исследования и включала изображения для 17 ячеек спутниковых сцен в системе WRS-2. Система WRS-2 (Worldwide Reference System) используется для определения местоположения снимков Landsat на земной поверхности. Отобранные снимки располагались в колонках (Path) с 174-й по 179-ю и в рядах (Row) с 23-го по 25-й. В общей сложности был отобран 51 космический снимок. Подборка спутниковых данных середины 1980-х гг. включала изображения с сенcopa Landsat TM. Подборка начала 2000-х гг. включала изображения с сенсоров Landsat TM, ETM+. Подборка 2018 г. включала изображения с сенсора Landsat OLI. Данные с сенсоров серии Landsat отбирались с учетом того, что должны характеризоваться отсутствием облачности, либо ее минимальным процентом.

Снимки Landsat были использованы для решения следующих задач. 1) Оцифровка контуров лесных массивов, для которой использовались снимки на первый временной срез (середина 1980-х гг.). 2) Автоматизированное выявление участков нарушенных лесов, появившихся в периоды 19852000 гг. и 2000-2018 гг. Снимки Sentinel в силу более высокого пространственного разрешения были использованы для повышения точности оцифровки контуров лесных массивов, картографируемых по данным Landsat.

Bce снимки Landsat прошли атмосферную и радиометрическую коррекцию, в результате которой они были пересчитаны в безразмерные коэффициенты спектральной яркости. Выполнение данного шага являлось необходимым условием количественного анализа изменений в спектрально-отражательных свойствах, которое проводилось в рамках выполнения следующей части исследования.

На следующем этапе для каждой спутниковой сцены (Path/Row) были вычислены растры разности коэффициентов отражения. Первая группа растров включала растры разности в период 19852000 гг. Вторая группа - в период 2000-2018 гг. Полученные изображения были в дальнейшем использованы для автоматизированного выявления участков нарушенных лесов.

Основной этап экспериментального исследования состоял в выявлении и картографировании участков лесов с нарушениями древостоя, появившихся в периоды 1985-2000 гг. и 2000-2018 гг. Вы- явление таких участков осуществляли с использованием специально разработанного для этой цели автоматизированного метода (Терехин, 2019) с последующей визуальной верификацией результатов. В основе предложенного подхода - применение функций классификации, позволяющих в автоматизированном режиме относить конкретный участок покрытой лесом площади к нарушенным, либо ненарушенным лесам. Функции классификации $(1,2)$, рассчитанные с применением дискриминантного анализа, представляют уравнения, вычисляющие для конкретного пикселя классификационный вес, на основе которого он относится к категории нарушенных лесов или лесов без признаков нарушений. Независимыми переменными в уравнениях выступают величины изменений коэффициентов спектральной яркости в трех спектральных диапазонах, рассчитанные на основе пар разновременных снимков Landsat, прошедших атмосферную и радиометрическую коррекцию.

$$
\begin{gathered}
\text { Нарушенные леса }= \\
=240.9 x_{1}+140 x_{2}+131.6 x_{3}-16.2, \\
\text { Ненарушенные леса }= \\
=-63.1 x_{1}+98.3 x_{2}+227.1 x_{3}-4.1,
\end{gathered}
$$

где $x_{1}, x_{2}, x_{3}-$ величины изменения коэффициентов отражения (коэффициентов спектральной яркости) в диапазонах SWIR1 (1.55-1.75 мкм), NIR (0.75-0.90 мкм) и SWIR2 (2.09-2.35 мкм) между начальной и конечной анализируемой датами. Точность выявления участков нарушенных лесов на основе приведенных функций составляет $90 \%$.

Минимальный размер выявляемых нарушений определялся, исходя из пространственного разрешения снимков Landsat, составляющего 30 м/пиксель. Преимущественно он был равен двукратному размеру пикселя, но, как показали результаты анализа полученных картограмм, в ряде случаев объективно выявлялись нарушения, по площади сопоставимые с размером пикселя. Такие ареалы, как правило, соответствовали относительно небольшим участкам выпадения древостоя в сосновых лесах.

Растры разности коэффициентов спектральной яркости вместе с подготовленным векторным слоем лесных массивов были использованы на входе алгоритма, написанного в геоинформационной среде ArcGIS, и использующего функции 1 и 2 для автоматизированного распознавания участков нарушенных лесных экосистем в каждый оцениваемый временной интервал. Растровые модели, характеризующие распространение нарушенных лесов, вычисляли для каждой спутниковой сцены Landsat, после чего на их основе в геоинформационной среде подготовили 
картограммы нарушенных лесов в пределах всего региона исследования.

Все рассчитанные картограммы прошли последовательную визуальную проверку методом их сопоставления с разновременными спутниковыми снимками. Проверка состояла в выявлении и редактировании ошибок автоматизированного дешифрирования, обусловленных наличием небольших теней от лесных массивов, преимущественно расположенных на склонах, а также наличием теней от небольших фрагментов облачности.

С использованием полученных материалов удалось выполнить оценку следующих характеристик нарушенных лесных экосистем:

- доля нарушенных лесов от общей площади лесных массивов в целом и в областях Центрального Черноземья в периоды 1985-2000 гг. и 20002018 гг. Общая площадь лесных массивов оценивалась в границах по состоянию на середину 1980-х гг.;

- особенности территориального распространения лесных экосистем с нарушенным древостоем в соответствующие периоды времени;

- пространственные и временные особенности распространения ареалов нарушенности в разных типах лесных насаждений (лиственных, хвойных, смешанных).

Подготовленные в рамках исследования картограммы нарушенных лесов в конце XX в. и начале XXI в. позволили построить на их основе карту категорий лесных экосистем, различающихся по времени, прошедшему с момента последних проявлений нарушающих факторов, отразившихся в древостое.

Лесные экосистемы по совокупности критериев, среди которых одним из ключевых является время, прошедшее с момента последней сплошной рубки, пожара и иного негативного воздействия могут быть разделены на различные категории нарушенности, включая сильнонарушенные, средненарушенные, слабонарушенные и ненарушенные (Бабинцева и др., 2008). На основе спутниковых данных не представляется возможным полноценно учесть некоторые критерии нарушенности, касающиеся нижних ярусов. Тем не менее, сроки последнего воздействия негативных факторов достаточно достоверно могут быть определены по разновременным снимкам. В связи с этим на основе данного фактора в настоящем исследовании было выполнено картографирование лесных массивов. Сильнонарушенными считали лесные экосистемы, в которых влияние нарушающих факторов проявлялось последние 1820 лет, средненарушенными - лесные массивы, в которых оно составляло от 20-35 лет, слабонарушенными - 35 лет и более. Ненарушенные лесные экосистемы на территории исследования, вследствие ее длительного аграрного освоения, практически отсутствуют и представлены только небольшими ареалами в пределах участка “Лес на Ворскле" заповедника "Белогорье” (Белгородская область).

В соответствии с используемой градацией, леса, в которых были зафиксированы нарушения в период 2000-2018 гг., попадают в категорию сильнонарушенных. Леса с нарушениями, появившимися в период 1985-2000 гг. соответствуют средненарушенным, лесные экосистемы без признаков нарушений древостоя в оба анализируемых периода (1985-2000 гг. и 2000-2018 гг.) - слабонарушенным. С использованием подготовленной картограммы была оценена площадь категорий, отличающихся по времени влияния негативных воздействий на древостой и выполнена их территориальная оценка.

\section{РЕЗУЛЬТАТЫ И ИХ ОБСУЖДЕНИЕ}

Картограммы, характеризующие участки нарушенных лесных экосистем, появившихся в периоды 1985-2000 гг. и 2000-2018 гг. (фрагменты представлены на рис. 2) позволили территориально оценить нарушенность древостоя лесных массивов и ее особенности в конце XX-начале XXI века в пределах лесостепной зоны Центрального Черноземья и провести ее сравнение в соответствующие периоды времени.

На основе полученных данных удалось также получить серию количественных параметров, характеризующих изменение нарушенности древостоя лесных массивов. Согласно полученным результатам (табл. 2) установлено, что нарушенность древостоя лесных экосистем в первые десятилетия XXI века была значительно выше, чем в последние десятилетия XX века. Из данных таблице 2 видно, что если в 1985-2000 гг. доля нарушенных участков в лесных массивах составляла $2.5 \%$ от общей площади лесов, то в период 20002018 гг. этот показатель составил 6\%. При этом в оба промежутка времени нарушенность древостоя лиственных лесов была ниже нарушенности хвойных или смешанных лесных массивов.

Если в последних десятилетиях XX века доля нарушенных лесных экосистем в различных типах лесных насаждений была примерно одинаковой, составляя $1.9 \%$ в лиственных лесах, $3.7 \%$ в смешанных лесах и $2.0 \%$ в хвойных лесах, то в начале XXI века наблюдается значительный рост нарушенности древостоя хвойных насаждений (пример на рис. 3). Похожая тенденция характерна и для многих ареалов лесов хвойного породного состава, расположенных в смешанных лесных массивах.

На основе анализа разновременных спутниковых снимков и материалов полевых наблюдений установлено, что причины нарушенности древо- 

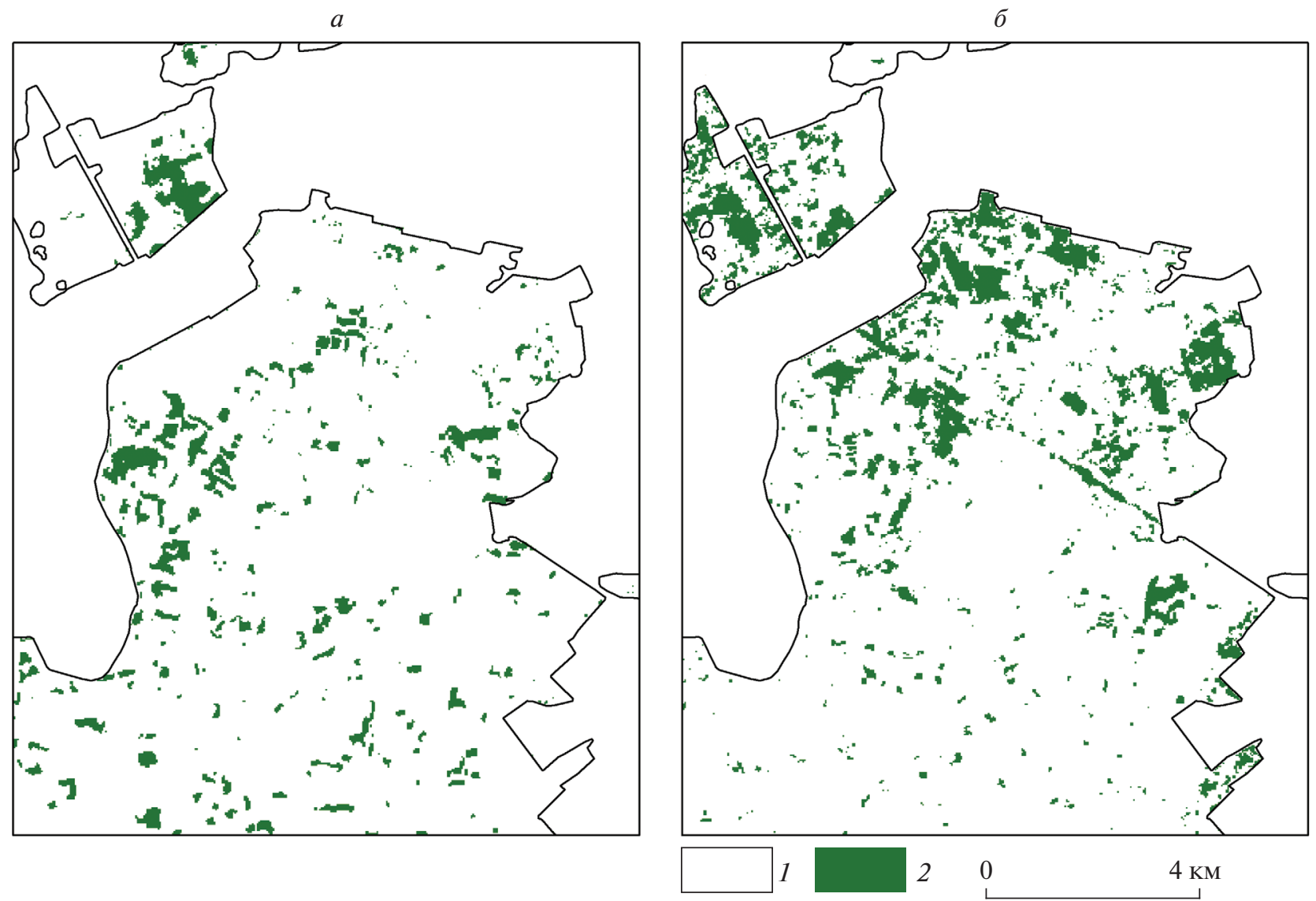

Рис. 2. Примеры фрагментов картограмм участков нарушенных лесных экосистем, появившихся в 1985-2000 гг. ( $a$ ) и 2000-2018 гг. (б), участок территории Липецкой области. 1 - границы лесных массивов, 2 - участки лесных экосистем с нарушениями древостоя.

стоя в лиственных и хвойных лесах различны. В хвойных (сосновых) лесах в начале XXI века основными факторами нарушенности выступали болезни деревьев и пожары, к которым в первую очередь относятся пожары 2010 года (Зиновьева, 2010). В лиственных лесах основным нарушаю- щим фактором, в конце XX в. и начале XXI века, являлись сплошные лесосечные рубки. Первые десятилетия XXI века отличаются от последних десятилетий XX века, в частности, тем, что в сосновых лесах наблюдается значительный рост ареалов выпадения древостоя хвойных лесов, кото-

Таблица 2. Доля лесных экосистем с нарушениями древостоя от общей площади земель, покрытых лесом на территории лесостепи Центрального Черноземья

\begin{tabular}{l|c|c|c|c|c|c|c|c}
\hline \multirow{2}{*}{\multicolumn{1}{c|}{ Регион }} & \multicolumn{9}{|c|}{ Доля лесов с нарушенным древостоем, \% } \\
\cline { 2 - 8 } & \multicolumn{2}{|c|}{ леса в целом } & \multicolumn{2}{|c|}{ лиственные } & \multicolumn{2}{c}{ смешанные } & \multicolumn{2}{c}{ хвойные } \\
\cline { 2 - 8 } & $1985-2000$ & $2000-2018$ & $1985-2000$ & $2000-2018$ & $1985-2000$ & $2000-2018$ & $1985-2000$ & $2000-2018$ \\
\hline Белгородская область & 2.0 & 2.1 & 2.0 & 0.9 & 1.3 & 6.5 & 2.6 & 18.4 \\
Воронежская область & 2.1 & 9.7 & 1.4 & 2.3 & 4.3 & 15.6 & 2.0 & 25.0 \\
Курская область & 1.1 & 3.4 & 1.0 & 3.2 & 1.4 & 4.5 & 1.6 & 6.2 \\
Липецкая область & 2.6 & 8.8 & 2.8 & 4.4 & 3.3 & 12.9 & 2.3 & 9.7 \\
Орловская область & 2.1 & 2.2 & 1.6 & 1.7 & 3.3 & 3.4 & 1.5 & 1.9 \\
Тамбовская область & 3.5 & 5.6 & 2.7 & 3.6 & 3.8 & 6.4 & 1.7 & 3.2 \\
Всего & 2.5 & 6.0 & 1.9 & 2.6 & 3.7 & 8.6 & 2.0 & 18.4 \\
\hline
\end{tabular}


Landsat-5 23.08.1988

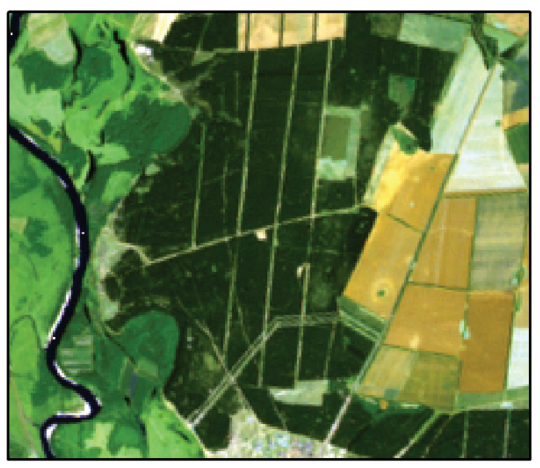

Landsat-5 05.08.2000

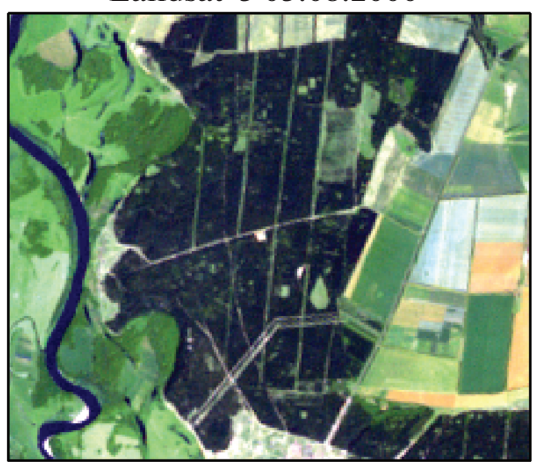

Landsat-5 05.08.2000

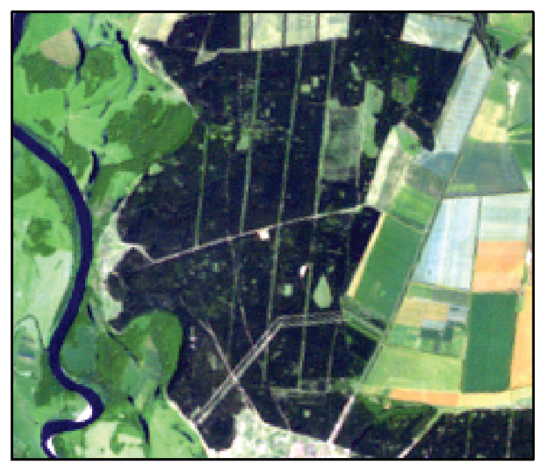

Landsat-5 26.08.2018

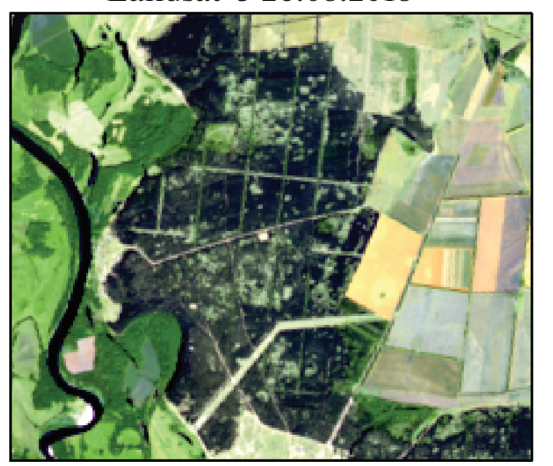

Участки нарушенности

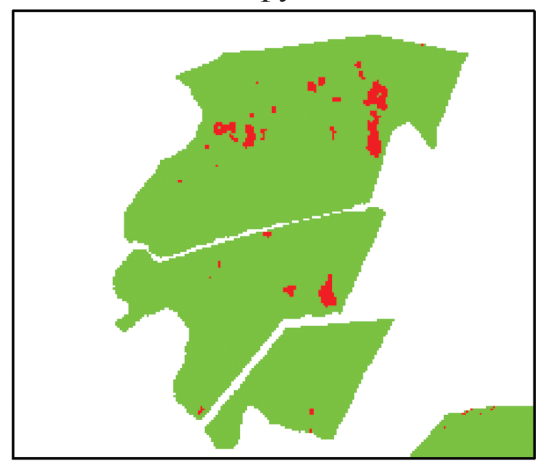

Участки нарушенности

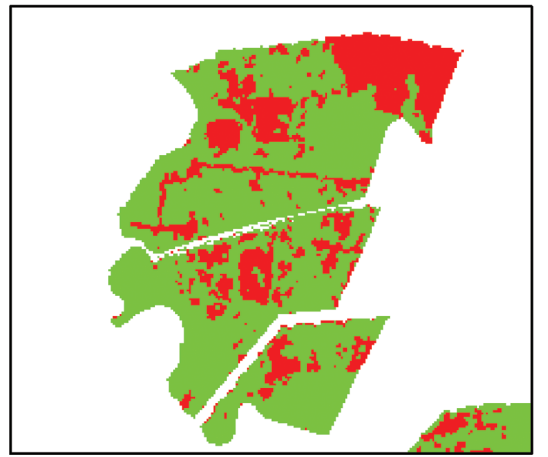

1

0

$2 \mathrm{KM}$

Рис. 3. Примеры автоматизированного выявления лесов с нарушениями древостоя с использованием предложенного метода (Воронежская область).

рое обусловлено воздействием болезней. Такие участки представляют собой сложные по форме площади, на которых происходит полное или частичное усыхание сосен. Следствием этого является значительное изреживание древостоя хвойных лесов.

Пространственные особенности в распространении нарушенных лесов, а также изменение доли нарушенных лесных массивов с 1985-2000 гг. по 2000-2018 гг. были изучены на основе специально подготовленной картограммы. Она характеризовала долю нарушенных лесных экосистем, на которую произошло изменение, от общей площади лесов в ячейках сети $30 \times 30$ км (рис. 4). Для анализа использовали те же ячейки, в пределах которых проводили картографирование исследуемых лесных экосистем на начальном этапе исследования. После этого изучили территориальные особенности распространения нарушенных ареалов в лиственных, хвойных и смешанных лесных насаждениях.

Из картограммы видно, что на основной части региона доминируют пространства, на которых доля нарушенных лесов с конца XX в. по начало XXI в. незначительно выросла (на 1-5\%). При этом в некоторых его частях этот рост составил бо- лее 50\%. Наибольший контраст в изменении доли нарушенных лесов от общей площади лесных экосистем наблюдается между юго-западной (Белгородская область) и юго-восточной (Воронежская область) частями территории исследования.

Среди областей Центрального Черноземья наибольшая концентрация ячеек, в которых произошло снижение доли нарушенных лесных экосистем, сосредоточена в Белгородской области. Для территории Воронежской области характерна обратная тенденция - в ней представлена наибольшая концентрация ячеек с увеличением, в том числе, значительным, доли нарушенных лесов. Снижение доли нарушенных лесов в Белгородской области во многом обусловлено законодательным отнесением основной части лесных массивов региона в 1991 г. к категории защитных и водоохранных насаждений, в связи с чем, промышленные лесозаготовки в них были запрещены.

В целом по региону в общей структуре нарушенных лесных экосистем произошло снижение на $59 \%$ доли лиственных лесов и более чем 4-кратное увеличение доли хвойных лесов (табл. 3). Т.е. рост доли лесов с нарушенными ярусами от общей площади, покрытой лесом, в значительной степени произошел за счет увеличения доли нарушен- 


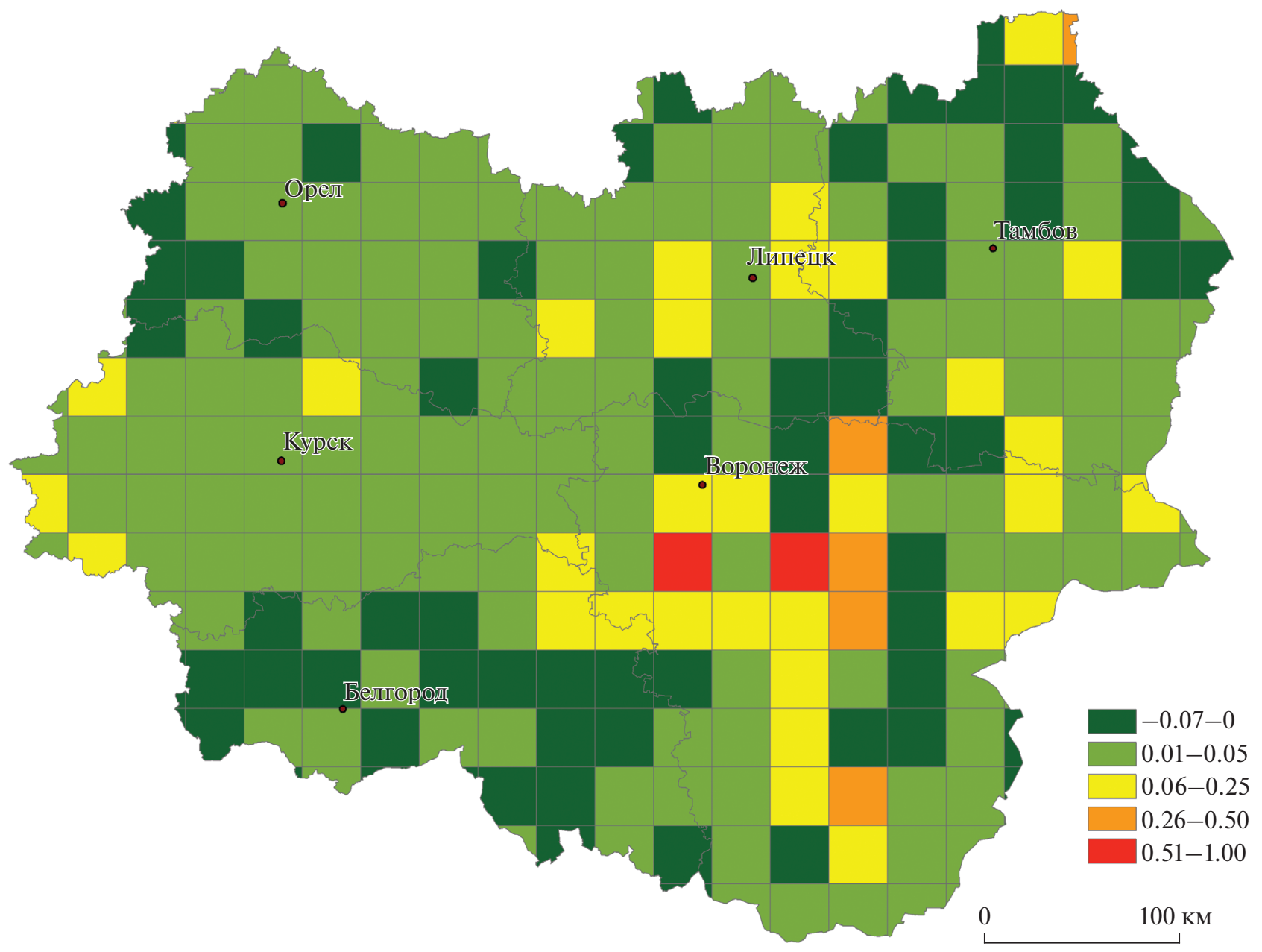

Рис. 4. Изменение доли нарушенных лесных экосистем от общей площади лесов с периода 1985-2000 гг. по период 2000-2018 гг. на территории Центрального Черноземья.

ных хвойных лесных насаждений, суммарная площадь которых выросла почти в 10 раз. Увеличение площади нарушенных лесов в смешанных лесных массивах также произошло в основном за счет ареалов хвойных насаждений.

Таким образом, в начале XXI века в сравнении с концом XX в. наблюдается увеличение доли нарушенных лесных экосистем от общей площади лесов, происходящее преимущественно за счет хвойных лесных насаждений.
Картографирование участков лесных экосистем, нарушенных в периоды 1985-2000 гг. и 2000-2018 гг. позволило с использованием операций наложения в геоинформационной среде подготовить карту категорий нарушенности лесных экосистем лесостепной зоны (рис. 5), отличающихся по времени возникновения нарушений в древостое, обусловленных влиянием сплошных лесосечных рубок, пожаров, воздействием насекомых-вредителей или болезней.

Таблица 3. Доля разных типов лесных насаждений в общей структуре лесов с нарушенным древостоем

\begin{tabular}{|c|c|c|c|c|c|}
\hline \multirow{2}{*}{$\begin{array}{l}\text { Тип лесных } \\
\text { насаждений }\end{array}$} & \multicolumn{2}{|c|}{ Площадь нарушенных лесов, га } & \multicolumn{2}{|c|}{$\begin{array}{c}\text { Доля в общей площади } \\
\text { нарушенных лесов, \% }\end{array}$} & \multirow{2}{*}{$\begin{array}{c}\text { Изменение } \\
\text { с 1985-2000 гг. } \\
\text { по 2000-2018 гг. }\end{array}$} \\
\hline & 1985-2000 гг. & $2000-2018$ гг. & 1985-2000 гг. & $2000-2018$ гг. & \\
\hline Лиственные & 12121.3 & 16565.0 & 0.41 & 0.24 & 0.59 \\
\hline Смешанные & 15923.9 & 37541.9 & 0.54 & 0.54 & 1.01 \\
\hline Хвойные & 1592.9 & 15071.0 & 0.05 & 0.22 & 4.05 \\
\hline
\end{tabular}




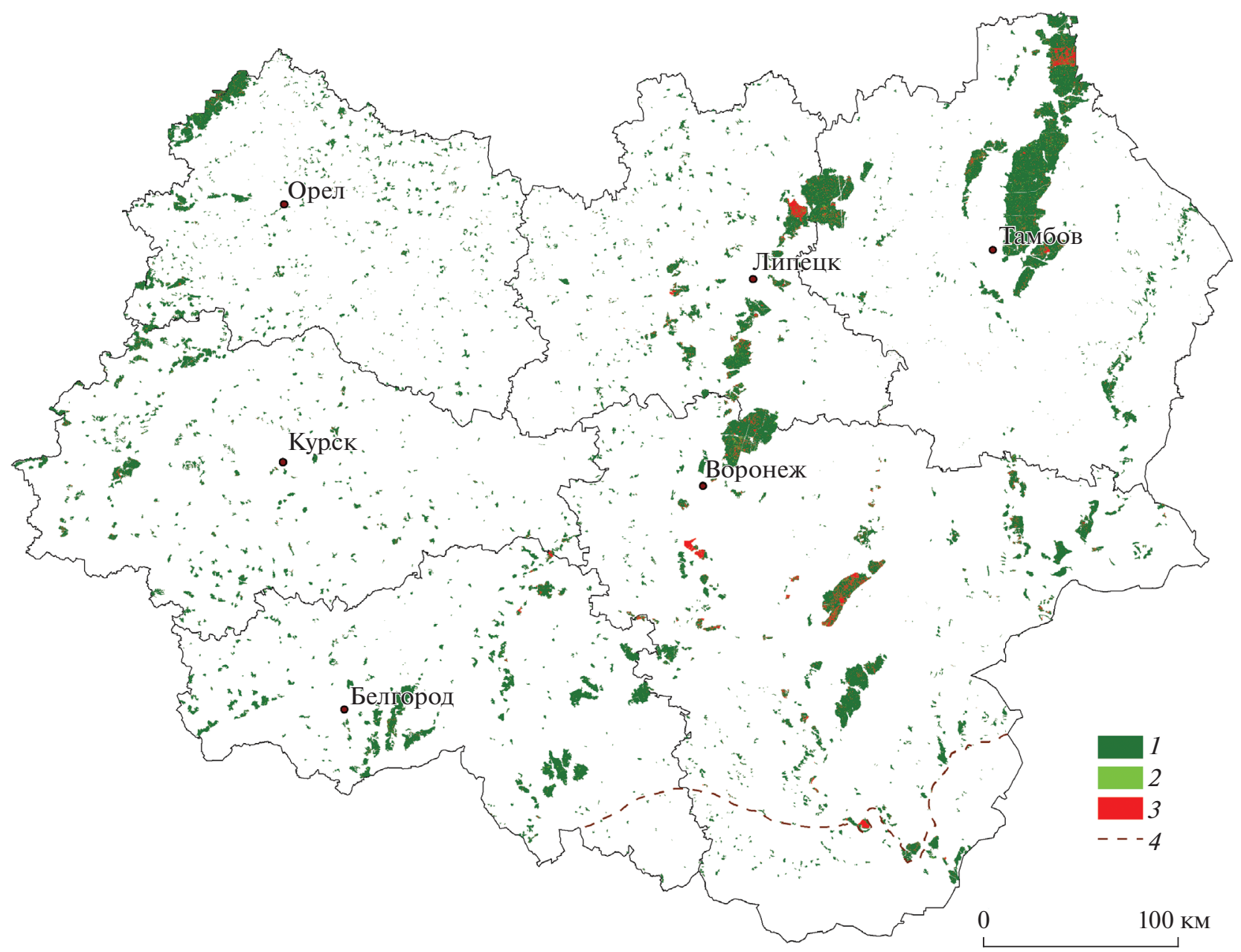

Рис. 5. Картограмма категорий лесных экосистем лесостепной зоны Центрального Черноземья по времени последнего проявления в древостое нарушающих факторов. 1 - слабонарушенные, 2 - средненарушенные, 3 - сильнонарушенные, 4 - граница лесостепи и степи.

На основе полученной картограммы выполнили оценку доли различных категорий нарушенности лесных экосистем в регионах Центрального Черноземья (табл. 4).
В соответствии с используемой градацией сильнонарушенные лесные экосистемы - леса с нарушениями древостоя, появившимися в период 2000-2018 гг., средненарушенные - леса с наруше-

Таблица 4. Распределение категорий лесов, отличающихся по времени последнего проявления в древостое нарушающих факторов, в областях Центрального Черноземья

\begin{tabular}{l|c|c|c}
\hline \multirow{2}{*}{\multicolumn{1}{c|}{ Регион }} & \multicolumn{3}{|c}{ Доля различных категорий нарушенности, \% } \\
\cline { 2 - 4 } & слабонарушенные & средненарушенные & сильнонарушенные \\
\hline Белгородская область & 95.8 & 2.0 & 2.2 \\
Воронежская область & 88.3 & 1.8 & 9.9 \\
Курская область & 95.4 & 1.0 & 3.5 \\
Липецкая область & 88.6 & 2.4 & 9.0 \\
Орловская область & 95.8 & 2.0 & 2.2 \\
Тамбовская область & 91.0 & 3.3 & 5.7 \\
Всего & 91.6 & 2.3 & 6.1 \\
\hline
\end{tabular}


ниями, появившимися в период 1985-2000 гг. Слабонарушенные - леса без нарушений древостоя в оба анализируемых периода.

Из данных в табл. 4 видно, что на основной части лесостепной зоны Центрального Черноземья доминируют слабонарушенные лесные экосистемы, т.е. леса, в древостое которых нарушения не наблюдались на снимках Landsat, начиная с середины 1980-х гг. по настоящее время. Т.е. более $90 \%$ лесных экосистем региона с этого времени не испытывали существенных нарушений древостоя вследствие пожаров, болезней, сплошных рубок или иных факторов.

Картограмма категорий нарушенности показывает, что площади лесов, нарушенных в начале XXI века значительно больше площади лесов, нарушенных в последние десятилетия XX века. Из нее также видно доминирование в пределах лесостепи Центрального Черноземья лесных экосистем без существенных нарушений древостоя за весь период, охватываемый в исследовании.

\section{ЗАКЛЮЧЕНИЕ}

1. На основе материалов разновременной космической съемки Landsat TM, ETM+, OLI впервые проведено сравнение нарушенности древостоя лесных экосистем лесостепи в конце XX в. и начале XXI века с использованием средств геоинформационного картографического анализа.

2. Доля лесных экосистем, древостой которых были нарушен вследствие сплошных лесосечных рубок, пожаров, болезней или насекомых-вредителей, на территории лесостепной зоны Центрального Черноземья выросла с $2.5 \%$ в $1985-$ 2000 гг. до 6\% в 2000-2018 гг. В значительной степени этот рост обусловлен увеличением нарушенности хвойных лесов, которая выросла более чем в 9 раз. Нарушенность широколиственных лесов выросла незначительно.

3. Основной тенденцией в изменении нарушенности древостоя лесных экосистем лесостепи является постепенной увеличение доли погибших от болезней хвойных лесов, которое усиливается с начала XXI века и еще не наблюдалось в таких масштабах в конце XX века. Для лиственных лесов тенденций изменения нарушенности не установлено.

4. В структуре нарушенных лесных экосистем доля лиственных лесов с конца XX в. по начало XXI в. снизилась на 41\%, доля хвойных лесов выросла более чем в 4 раза. Наиболее контрастны в отношении изменения нарушенности лесов югозападная и юго-восточная часть лесостепи ЦЧР.

5. Несмотря на рост площадей лесов с нарушенным древостоем в исследуемый период времени, в начале XXI века более 90\% лесных экосистем составляют лесные массивы, в которых воз- действие нарушающих факторов в древостое не проявлялось как минимум с середины 1980-х гг.

\section{ИСТОЧНИК ФИНАНСИРОВАНИЯ}

Исследование выполнено за счет гранта Российского научного фонда (проект № 18-77-00049).

\section{СПИСОК ЛИТЕРАТУРЫ}

Бабиниева Р.М., Горбачев В.Н., Лебедева А.А. Применение методов картографии при планировании и ведении лесопаркового хозяйства // Изв. Оренбургского государственного аграрного университета. 2008. Т. 3. № 19-1. C. 45-48.

Барталев С.А., Курятникова Т.С., Стибиг Х.Ю. Методы использования временных серий спутниковых изображений высокого пространственного разрешения для оценки масштабов и динамики вырубок таежных лесов // Современные проблемы дистанционного зондирования Земли из космоса. 2005. Т. 2. № 2. С. 217-227.

Барталев С.А., Стыценко Ф.В., Егоров В.А., Лупян Е.А. Спутниковая оценка гибели лесов России от пожаров // Лесоведение. 2015. № 2. С. 83-94.

Бондур В.Г., Воробьев В.Е. Космический мониторинг импактных районов Арктики // Исслед. Земли из космоса. 2015. № 4. С. 4-24.

https://doi.org/10.7868/S0205961415040028

Борзов С.М., Потатуркин О.И. Обнаружение выборочных рубок леса по данным дистанционных измерений высокого пространственного разрешения // Исслед. Земли из космоса. 2014. № 4. С. 87-93.

https://doi.org/10.7868/S0205961414030026

Воробьев О.Н., Курбанов Э.А., Полевщикова Ю.А., Лежнин C.A. Оценка динамики и нарушенности лесного покрова в Среднем Поволжье по снимкам Landsat // Современные проблемы дистанционного зондирования Земли из космоса. 2016. Т. 13. № 4. С. 124-134.

Зиновьева И.С. Оценка использования ресурсного потенциала лесов на территории Воронежской области // Региональная экономика: теория и практика. 2012. № 10. C. $24-30$.

Плотникова А.С., Ершов Д.В., Харитонова А.О., Шуляк П.П., Барталев С.А., Стыценко Ф.В. Пространственная оценка современных пожарных режимов лесных экосистем России // Современные проблемы дистанционного зондирования Земли из космоса. 2019. Т. 16. № 5. C. $228-240$.

Потапов П.В., Журавлева И.В., Маниша А.Е., Турубанова С.А., Ярошенко А.Ю. Выявление и мониторинг дистанционными методами малонарушенных лесных территорий мира // Лесоведение. 2008. № 2. С. 58-67.

Стыценко Ф.В., Барталев С.А., Букась А.В., Ершов Д.В., Сайгин И.А. Возможности пролонгированной оценки постпожарного состояния хвойных вечнозеленых лесов по данным многоспектральных спутниковых измерений // Современные проблемы дистанционного зондирования Земли из космоса. 2019. Т. 16. № 5. C. $217-227$.

Терехин Э.А. Распознавание нарушенных лесных экосистем лесостепи на основе спектрально-отража- 
тельных характеристик // Компьютерная оптика. 2019. T. 43. № 3. С. 412-418.

Харин Н.Г., Татеиши Р. Применение снимков NOAA/ AVHRR для изучения фенологии лесов России // Лесоведение. 2003. № 2. С. 10-17.

Харченко Н.А., Харченко Н.Н. К вопросу о деградации порослевых дубрав Центрального Черноземья // Вестник Московского государственного университета леса Лесной вестник. 2007. № 4. С. 29-31.

Brooks E.B., Wynne R.H., Thomas V.A., Blinn C.E., Coulston J.W. On-the-fly massively multitemporal change detection using statistical quality control charts and Landsat data // IEEE Trans. Geosci. Remote Sensing. 2014. V. 52. P. 3316-3332. https://doi.org/10.1109/TGRS.2013.2272545

Healey S., Cohen W.B., Zhiqiang Y., Krankin O.N. Comparison of Tasseled Cap-based Landsat data structures for use in forest disturbance detection // Remote Sensing of Environment. 2005. V. 97. № 3. P. 301-310. https://doi.org/10.1016/j.rse.2005.05.009

Hermosilla T., Wulder M.A., White J.C., Coops N.C., Hobart G.W., Campbell L.B. Mass data processing of time series Landsat imagery: pixels to data products for forest monitoring // International J. Digital Earth. 2016. V. 9. P. 1035-1054. https://doi.org/10.1080/17538947.2016.1187673

Hislop S., Jones S., Soto-Berelov M., Skidmore A., Haywood A., Nguyen T.H. A fusion approach to forest disturbance mapping using time series ensemble techniques // Remote Sensing of Environment. 2019. V. 221. P. 188-197.

https://doi.org/10.1016/j.rse.2018.11.025

Huang C., Goward S.N., Masek J.G., Thomas N. An automated approach for reconstructing recent forest disturbance history using dense Landsat time series stacks // Re- mote Sensing of Environment. 2010. V. 114. P. 183-198. https://doi.org/10.1016/j.rse.2009.08.017

Kennedy R.E., Yang Z., Cohen W. B. Detecting trends in forest disturbance and recovery using yearly Landsat time series: 1. LandTrendr - Temporal segmentation algorithms // Remote Sensing of Environment. 2010. V. 114. № 12. P. 2897-2910.

https://doi.org/10.1016/j.rse.2010.07.008

Vogelmann J.E., Xian G., Homer C., Tolk B. Monitoring gradual ecosystem change using Landsat time series analyses: Case studies in selected forest and rangeland ecosystems // Remote Sensing of Environment. 2012. V. 122. P. 92-105.

https://doi.org/10.1016/j.rse.2011.06.027

White J.C., Wulder M.A., Hermosilla T., Coops N.C., Hobart G.W. A nationwide annual characterization of 25 years of forest disturbance and recovery for Canada using Landsat time series // Remote Sensing of Environment. 2017. V. 194. P. 303-321.

https://doi.org/10.1016/j.rse.2017.03.035

Zhao F., Huang C., Goward S.N., Schleeweis K., Rishmawi K., Lindsey M.A., Denning E., Keddell L., Cohen W.B., Yang Z., Dungan J.L., Michaelis A. Development of Landsat-based annual US forest disturbance history maps (1986-2010) in support of the North American Carbon Program (NACP) // Remote Sensing of Environment. 2018. V. 209. P. 312-326. https://doi.org/10.1016/j.rse.2018.02.035

Zhu Z., Woodcock C.E. Continuous change detection and classification of land cover using all available Landsat data // Remote Sensing of Environment. 2014. V. 144. P. 152-171. https://doi.org/10.1016/j.rse.2014.01.011

\title{
Change of Forest Ecosystems Disturbance in the Forest-Steppe Zone of the Central Chernozem Region at the End of the XX Century-Beginning of the XXI Century
}

\author{
E. A. Terekhin \\ Belgorod State University, Belgorod, Russia
}

\begin{abstract}
The results of assessing the forest ecosystems disturbance in the forest-steppe zone of the Central Chernozem region in the periods 1985-2000 and 2000-2018 are presented. Geoinformation mapping of disturbed forests areas that appeared during the corresponding time periods has been performed using an automated approach. The share of disturbed forest ecosystems in the forest-steppe zone of the Central Chernozem region increased from $2.5 \%$ at the end of the XX century to $6 \%$ at the beginning of the XXI century. The share of disturbed forest ecosystems in coniferous forests increased 9 times. In deciduous forests, the proportion of disturbed plots increased slightly. The increase in the share of disturbed forests was mainly due to an increase in the disturbance of coniferous forest ecosystems. Share of deciduous forests in the structure of disturbed forests decreased by almost 2 times. The map of categories of forest ecosystems disturbance has been prepared, which characterizes forests by the time elapsed since the last exposure to disturbing factors.
\end{abstract}

Keywords: forest, forest-steppe, forest ecosystems disturbance, remote sensing data, Landsat, Sentinel

\section{REFERENCES}

Babintseva R.M., Gorbachev V.N., Lebedeva A.A. Primenenie metodov kartografii pri planirovanii i vedenii lesoparkovogo khozyaystva [The use of mapping methods in woodpark husbanry planning and management] // Izvestiya
Orenburgskogo gosudarstvennogo agrarnogo universiteta. 2008. V. 3. № 19-1. P. 45-48 (In Russian).

Bartalev S.A., Kuryatnikova T.S., Stibig Kh.Yu. Metody ispol'zovaniya vremennykh seriy sputnikovykh izobrazheniy vysokogo prostranstvennogo razresheniya dlya otsenki masshtabov i dinamiki vyrubok taezhnykh lesov [Methods 
of using time series of satellite imagery of high spatial resolution to assess the scale and dynamics of deforestation of taiga forests] // Sovremennye problemy distantsionnogo zondirovaniya Zemli iz kosmosa. 2005. V. 2. № 2. P. 217227 (In Russian).

Bartalev S.A., Stytsenko F.V., Egorov V.A., Lupyan E.A. Sputnikovaya otsenka gibeli lesov Rossii ot pozharov [Satellitebased assessment of russian forest fire mortality] // Lesovedenie. 2015. № 2. P. 83-94 (In Russian).

Bondur V.G., Vorobev V.E. Satellite Monitoring of Impact Arctic Regions // Izvestiya, Atmospheric and Oceanic Physics. 2015. V. 51. № 9. P. 949-968. doi: 10.1134/S0001433815090054

Borzov S.M., Potaturkin O.I. Obnaruzhenie vyborochnykh rubok lesa po dannym distantsionnykh izmereniy vysokogo prostranstvennogo razresheniya [Detection of insignificant anthropogenic changes on the earth surface using remote sensing data] // Issledovanie Zemli iz kosmosa. 2014. № 4. P. 87-93 (In Russian). doi: 10.7868/S0205961414030026

Vorob'ev O.N., Kurbanov E.A., Polevshchikova Yu.A., Lezhnin S.A. Otsenka dinamiki i narushennosti lesnogo pokrova v Srednem Povolzh'e po snimkam Landsat [Assessment of dynamics and disturbance of forest cover in the Middle Povolzhje by Landsat images] // Sovremennye problemy distantsionnogo zondirovaniya Zemli iz kosmosa. 2016. V. 13. № 4. P. 124-134 (In Russian).

Zinov'eva I.S. Otsenka ispol'zovaniya resursnogo potentsiala lesov na territorii Voronezhskoy oblasti [Assessment of the use of forest resource potential in the Voronezh region] // Regional'naya ekonomika: teoriya i praktika. 2012. № 10. P. 24-30 (In Russian).

Plotnikova A.S., Ershov D.V., Kharitonova A.O., Shulyak P.P., Bartalev S.A., Stytsenko F.V. Prostranstvennaya otsenka sovremennykh pozharnykh rezhimov lesnykh ekosistem Rossii [Spatial assessment of modern forest fire regimes in Russia] // Sovremennye problemy distantsionnogo zondirovaniya Zemli iz kosmosa. 2019. V. 16. № 5. P. 228-240 (In Russian).

Potapov P.V., Zhuravleva I.V., Manisha A.E., Turubanova S.A., Yaroshenko A. Yu. Vyyavlenie i monitoring distantsionnymi metodami malonarushennykh lesnykh territoriy mira [Identification and monitoring of world intact landscapes using remote sensing methods] // Lesovedenie. 2008. № 2. P. 58-67 (In Russian).

Stytsenko F.V., Bartalev S.A., Bukas'A.V., Ershov D.V., Saygin I.A. Vozmozhnosti prolongirovannoy otsenki postpozharnogo sostoyaniya khvoynykh vechnozelenykh lesov po dannym mnogospektral'nykh sputnikovykh izmereniy [The possibilities of prolonged burnt severity assessment of evergreen coniferous forest using multi-spectral satellite data] // Sovremennye problemy distantsionnogo zondirovaniya Zemli iz kosmosa. 2019. V. 16. № 5. P. 217-227 (In Russian).

Terekhin E.A. Raspoznavanie narushennykh lesnykh ekosistem lesostepi na osnove spektral'no-otrazhatel'nykh kharakteristik [Detection of disturbed forest ecosystems in the forest-steppe zone using reflectance values] // Komp'yuternaya optika. 2019. V. 43. № 3. P. 412-418 (In Russian).
Kharin N.G., Tateishi R. Primenenie snimkov NOAA/AVHRR dlya izucheniya fenologii lesov Rossii [Application of NOAA/AVHRR images for studies of forest phenology in Russia] // Lesovedenie. 2003. № 2. P. 10-17 (In Russian).

Kharchenko N.A., Kharchenko N.N. K voprosu o degradatsii poroslevykh dubrav Tsentral'nogo Chernozem'ya [To the issue of degradation of coppice oak forests of the Central Black Earth Region] // Vestnik Moskovskogo gosudarstvennogo universiteta lesa - Lesnoy vestnik. 2007. № 4. P. 29-31 (In Russian).

Healey S., Cohen W.B., Zhiqiang Y., Krankin O.N. Comparison of Tasseled Cap-based Landsat data structures for use in forest disturbance detection // Remote Sensing of Environment. 2005. V. 97. № 3. P. 301-310. doi: 10.1016/j.rse.2005.05.009.

Hermosilla T., Wulder M.A., White J.C., Coops N.C., Hobart G.W., Campbell L.B. Mass data processing of time series Landsat imagery: pixels to data products for forest monitoring // International J. Digital Earth. 2016. V. 9. P. 1035-1054. doi: 10.1080/17538947.2016.1187673.

Hislop S., Jones S., Soto-Berelov M., Skidmore A., Haywood A., Nguyen T.H. A fusion approach to forest disturbance mapping using time series ensemble techniques // Remote Sensing of Environment. 2019. V. 221. P. 188-197. doi: 10.1016/j.rse.2018.11.025.

Huang C., Goward S.N., Masek J.G., Thomas N. An automated approach for reconstructing recent forest disturbance history using dense Landsat time series stacks // Remote Sensing of Environment. 2010. V. 114. P. 183-198. doi: 10.1016/j.rse.2009.08.017.

Kennedy R.E., Yang Z., Cohen W. B. Detecting trends in forest disturbance and recovery using yearly Landsat time series: 1. LandTrendr - Temporal segmentation algorithms // Remote Sensing of Environment. 2010. V. 114. № 12. P. 2897-2910. doi: 10.1016/j.rse.2010.07.008.

Vogelmann J.E., Xian G., Homer C., Tolk B. Monitoring gradual ecosystem change using Landsat time series analyses: Case studies in selected forest and rangeland ecosystems // Remote Sensing of Environment. 2012. V. 122. P. 92-105. doi: 10.1016/j.rse.2011.06.027.

White J.C., Wulder M.A., Hermosilla T., Coops N.C., Hobart G.W. A nationwide annual characterization of 25years of forest disturbance and recovery for Canada using Landsat time series // Remote Sensing of Environment. 2017. V. 194. P. 303-321. doi: 10.1016/j.rse.2017.03.035.

Zhao F., Huang C., Goward S.N., Schleeweis K., Rishmawi K., Lindsey M.A., Denning E., Keddell L., Cohen W.B., Yang Z., Dungan J.L., Michaelis A. Development of Landsat-based annual US forest disturbance history maps (1986-2010) in support of the North American Carbon Program (NACP) // Remote Sensing of Environment. 2018. V. 209. P. 312-326. doi: 10.1016/j.rse.2018.02.035.

Zhu Z., Woodcock C.E. Continuous change detection and classification of land cover using all available Landsat data // Remote Sensing of Environment. 2014. V. 144. P. 152-171. doi: $10.1016 /$ j.rse.2014.01.011. 